\title{
Molecular basis of Transabdominal-a sexually dimorphic mutant of the bithorax complex of Drosophila
}

(cis regulation/macromutation/homeotic/Abdominal B/evolution)

\author{
Susan E. Celniker and E. B. Lewis \\ Biology Division, California Institute of Technology, Pasadena, CA 91125 \\ Contributed by E. B. Lewis, November 5, 1992
}

\begin{abstract}
Transabdominal (Tab) is a dominant gain-offunction mutation that results in islands of sexually dimorphic abdominal cuticle in the dorsal thorax of the adult fly. This phenotype has complete penetrance and constant expressivity, and we show that it results from ectopic expression of ABD-BI, one of two proteins derived from the Abdominal B (Abd-B) domain of the bithorax complex (BX-C) and one that is normally expressed only in terminal portions of the abdomen. In $T a b /+$ animals ABD-BII is ectopically expressed in the relevant imaginal "wing" disc as three islands of cells whose location on the fate map corresponds to the three islands of transformed cuticle in each half of the adult thorax. Tab is associated with an inseparable inversion bringing sequences in 90E next to sequences in the transcription unit encoding ABD-BII in 89E. That 90E sequences drive ectopic expression of ABD-BII is indicated by our finding that such sequences in a $\boldsymbol{P}$-element transformant express the reporter gene's product $(\beta$-galactosidase) in the same three islands of wing disc cells. On morphological grounds, the transformed islands in the adult thorax correspond to subsets of muscle attachment cells. Ectopic expression of a homeodomain protein thus creates a unique and invariant pattern of sexual dimorphism.
\end{abstract}

Conspicuous sexual dimorphism in wild-type Drosophila melanogaster is largely confined to the posterior abdomen, where the male has solidly black tergites on the fifth abdominal (A5) and A6 segments and lacks tergites on A7 and A8, while the female has only black-banded tergites on A5-A8 inclusive. In $\mathrm{Tab} /+$ animals, the same strikingly dimorphic pattern of pigmentation also occurs on the dorsal thorax (T2) in the form of islands of abdominal-like cuticle that are solidly black pigmented in the male and only partially banded with black in the female (Fig. 1).

In wild type, the ability to differentiate properly the abdominal body segments depends on the expression of the homeotic genes of the bithorax complex (BX-C) (1). Development of $A 5$ and the more posterior segments of the abdomen is specified by the $A b d-B$ domain, one of three domains of the BX-C - the other two being Ultrabithorax $(U b x)$ and abdominal A (abd-A) (ref. 2; reviewed in ref. 3). The $A b d-B$ domain encodes two proteins, ABD-BI and ABD-BII (4). They share the same homeodomain, a 60-amino acid helix-turn-helix motif that mediates DNA-binding interactions and is also found in other proteins that regulate development (reviewed in ref. 5). In wild-type embryos, the ABD-B proteins have spatial distributions that are restricted to the posterior body regions (4). Later in development $A b d-B$ is expressed in the imaginal disc that gives rise to the adult internal and external genitalia (6).

To determine what role the $A b d-B$ domain plays in bringing about the $T a b /+$ phenotype, we have studied the pattern of

The publication costs of this article were defrayed in part by page charge payment. This article must therefore be hereby marked "advertisement" in accordance with 18 U.S.C. $\$ 1734$ solely to indicate this fact. protein and transcript expression in the larval wing discs and in embryos of $T a b /+$ animals. Here we provide evidence that ABD-BII is able to direct differentiation of abdominal tissues in $\mathrm{T} 2$ in the absence of other abdominal genes of the BX-C.

\section{MATERIALS AND METHODS}

Materials. We were provided with gifts of materials as follows: a monoclonal anti-UBX (Ultrabithorax) antibody was from R. Mann and D. Hogness (Department of Biochemistry, Stanford University; originally made by $\mathbf{R}$. White and M. Wilcox), monoclonal anti-ABD-A (abdominal A) antibody was from I. Duncan (Department of Biology, Washington University, St. Louis), and the B14 P-element strain was from R. Kolodkin and C. Goodman (Department of Molecular and Cellular Biology, University of California, Berkeley).

Immunohistochemistry. Wing discs were dissected from third-instar larvae in $1 \times$ TBS $(0.1 \mathrm{M}$ Tris/1.29 M NaCl/0.05 $\mathrm{M} \mathrm{KCl} / 0.01 \mathrm{M}$ EGTA, pH 8.0)/0.1\% Triton X-100 and fixed for $5 \mathrm{~min}$ in $2 \% \mathrm{EM}$-grade formaldehyde (Polysciences). The discs were serially incubated with a monoclonal anti-ABD-B antibody (1A2E9) (4), biotinylated anti-immunoglobulin antibody (Bio-Rad), and avidin DH-biotinylated antihorseradish peroxidase $\mathrm{H}$ complex (Vector Laboratories). Discs were then stained with the peroxidase substrate diaminobenzidine tetrahydrochloride $(1 \mathrm{mg} / \mathrm{ml})$ (Polysciences) and $0.01 \%$ hydrogen peroxidase.

Embryos (3-15 hr old) were fixed and protein was localized as described (4).

In Situ Hybridization and Tissue Localization. Wing discs were dissected from third-instar larvae in $1 \times$ phosphatebuffered saline (PBS) and fixed three times: first in $4 \%$ paraformaldehyde in $1 \times$ PBS for $5 \mathrm{~min}$ at room temperature and $15 \mathrm{~min}$ at $4^{\circ} \mathrm{C}$, second in $4 \%$ paraformaldehyde/1X PBS $/ 0.6 \%$ Triton X-100 (PBT) for $5 \mathrm{~min}$ at room temperature, and third after treatment with proteinase $K(10 \mathrm{mg} / \mathrm{ml}$ in PBT) for 3 min in $4 \%$ paraformaldehyde $/ 0.2 \%$ glutaraldehyde in PBS for $15 \mathrm{~min}$ at room temperature. Hybridization conditions were as described (7). Embryos were prepared and hybridization conditions were as described (7). Antisense single-stranded probes labeled with digoxigenin were generated by PCR. Transcripts encoding ABD-BI (also called class A transcripts) and ABD-BII (class B) were detected by PCR-generated anti-sense probes 5013 and 5005, respectively. Their position on the genomic map relative to the $A b d-B$ cDNAs is shown in Fig. 2. Probe 5013 was generated by using a 1327-bp BssHII genomic restriction fragment from +157 on the BX-C walk and the primer 5'-TACTCGAGTTCTGCCCC-3'. Probe 5005 was generated by using a 1145-bp Spe I/Sca I genomic restriction fragment from +187 on the BX-C walk and the primer 5'-CCGCTGATTAAT-

Abbreviations: BX-C, bithorax complex; T2, second thoracic segment; A5, etc., fifth abdominal segment, etc. 


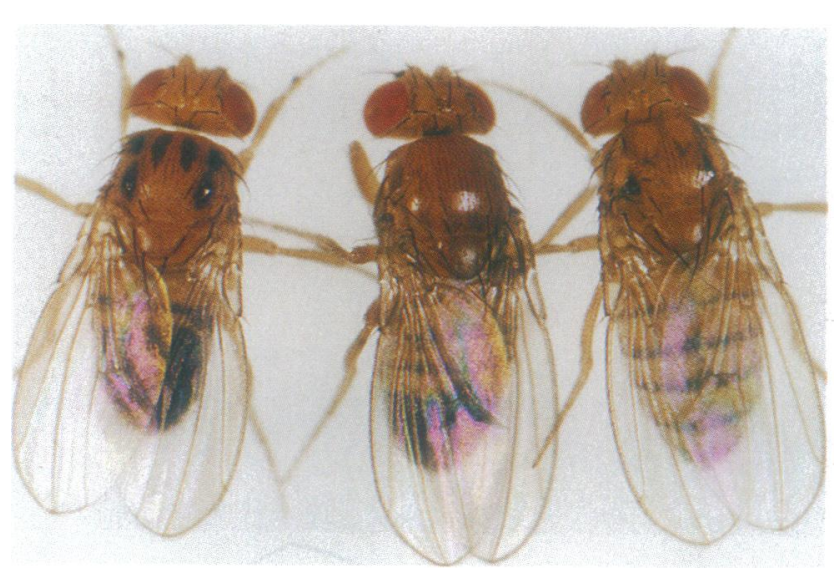

FIG. 1. Sexual dimorphism in the thorax of $T a b /+$ male and female compared with wild type. (Left to Right) Tab/+ male with three solidly black-pigmented islands on each half of $T 2$, wild-type male with uniformly tan-colored T2 (the wild-type female being identical), $T a b /+$ female with islands in $\mathrm{T} 2$ that are only black banded.

TCAAG-3'. Discs and embryos were photographed with Nomarski optics.

5-Bromo-4-chloro-3-indolyl $\beta$-D-galactoside staining of discs from the B14 line was as described (13).

\section{RESULTS}

In $T a b /+$ wing discs, we detect ABD-B protein principally in three regions whose location in the fate map of the disc correlates remarkably well with the three islands of abdominal-like cuticle in each half of the adult T2 (Fig. 3A). We have confirmed by in situ hybridization that such discs express the transcript encoding ABD-BII protein (Fig. 3B). We fail to detect transcripts encoding ABD-BI in these discs, nor do we detect either UBX or ABD-A protein (data not shown). [ABD-BI and ABD-BII are also known as $A b d-B \mathrm{~m}$ and $A b d-B$ r, respectively (15).] We conclude that ectopic expression of ABD-BII is responsible for the $T a b /+$ transformation in $\mathrm{T} 2$.

That enhancer-like elements in $90 \mathrm{E}$ drive ectopic expression of ABD-B in $T a b /+$ discs is made likely by results of studying a germ-line transformant (B14) having a $P$-element inserted in $90 \mathrm{E}$. In an otherwise wild-type background, the reporter gene in this case, $\beta$-galactosidase, is expressed in the same three islands of wing disc cells (Fig. $3 C$ ) that in $T a b /+$ discs express ABD-B protein and transcripts encoding ABDBII.

In $\mathrm{T} 2$ of $T a b /+$ animals, the position of the sexually dimorphic cuticle coincides with the position of subsets of muscle attachment sites (Fig. 4). We presume that the cells in such sites secrete cuticle as well as having a muscle attachment function. If so, the cuticular transformation in T2 of $T a b /+$ is a homeotic one in which ectopic expression of ABD-BII causes thoracic-type cuticle to be replaced by abdominal-like cuticle typical of the terminal half of the abdomen.

Indirect evidence suggests that $T a b /+$ animals are globally expressing ABD-B protein and transcripts for ABD-BII in subsets of muscle attachment cells throughout the animal. Thus, such expression is seen in groups of ectodermal cells in virtually all segments of the $T a b /+$ embryo (Fig. 5). At a

iab-5

iab- 6

iab-7

$A b d-B$ iab-8

iab-9

\begin{tabular}{|c|c|c|c|c|c|}
\hline & & $\begin{array}{r}5013 \\
\square \\
\end{array}$ & Probe & 5005 & $\downarrow$ Probe \\
\hline+100 & +150 & & & & $89 \mathrm{E} / 90 \mathrm{E}^{+200 \mathrm{~kb}}$ \\
\hline
\end{tabular}

ABD-BI
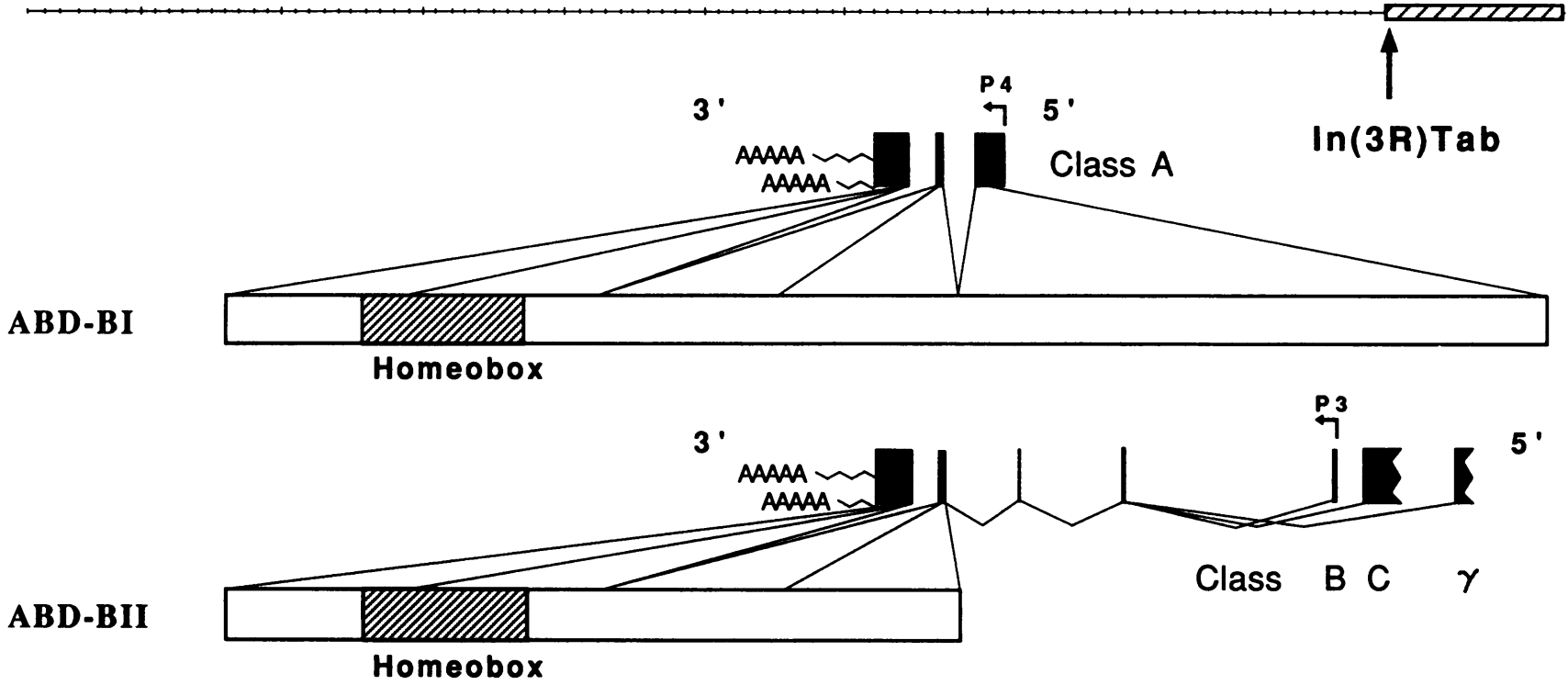

Fig. 2. Organization of wild-type and $\operatorname{In}(3 R) T a b$ genomic DNA and representative homeobox-containing $\mathrm{cDNAs}$ from the $A b d-B$ domain $(4,8,9)$. The $A b d-B$ domain extends approximately from +100 to $+200 \mathrm{~kb}$ of the BX-C walk $(10)$. The $i a b-5-i a b-9$ regions are delineated by brackets (11). Boldfaced arrow points to Tab breakpoint. Tab is associated with a small inversion with breakpoints in $89 \mathrm{E}$ and $90 \mathrm{E}$ of the salivary gland chromosomes (6). Four classes of $A b d-B$ transcripts are designated A, B, C, and $\gamma(12)$. Class A transcripts encode ABD-BI and class $\mathrm{B}, \mathrm{C}$, and $\gamma$ transcripts encode ABD-BII. Transcription start sites for classes A and B are marked with bent arrows and are designated P4 and $\mathrm{P} 3$, respectively. Molecular breakpoint in $89 \mathrm{E}$ is located in a $5^{\prime}$ nontranslated exon of class $\mathrm{C}$ and 4315 bp from the transcription start site $\mathrm{P} 3$ for class $B$. 

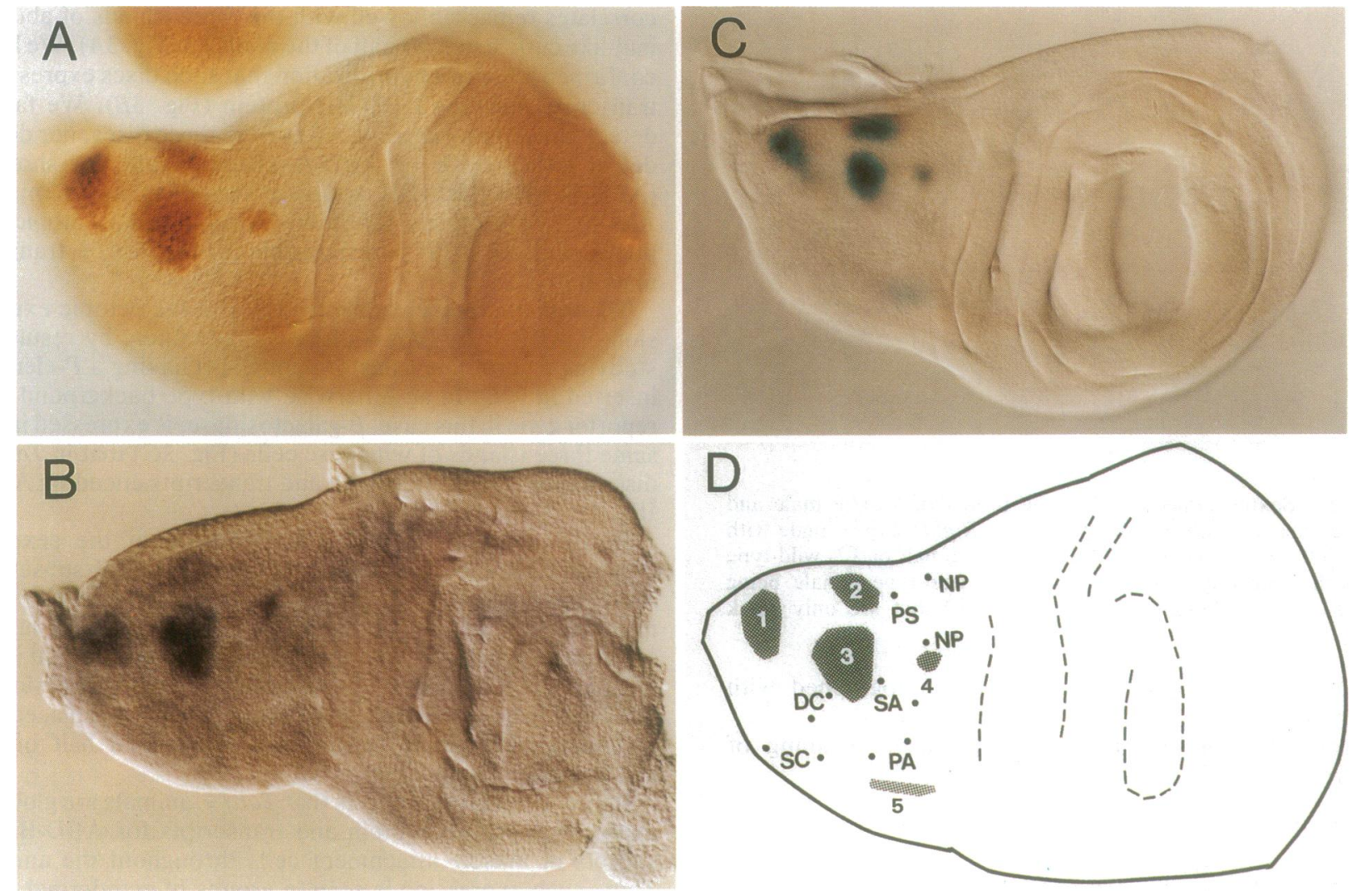

Fig. 3. Comparison of ABD-B protein and transcript expression patterns in $T a b /+$ wing discs with the pattern of $\beta$-galactosidase expression in a disc from a $P$-element transformant. $(A)$ ABD-B protein in a Tab/+ disc. (B) RNA encoding ABD-BII in a Tab/+ disc. Since the ABD-B antibody is directed against an epitope common to both ABD-BI and ABD-BII proteins, it has been necessary to determine the distribution of transcripts encoding these proteins in order to identify the ectopically expressed one(s). (C) $\beta$-Galactosidase staining in a disc from $P$-element transformant B14. (D) Diagram of the wing disc in $A$ superimposed on the fate map of the wild-type disc [modified from Bryant (14)]; ABD-B-expressing regions of the disc are shown stippled and numbered. Location of presumptive bristle primordia in the wing disc is shown by solid circles. Dashed lines outline the region of the disc that gives rise to the wing tissue. Two small islands, numbered 4 and 5 , of ABD-B protein expression fail to have a discernible effect on the cuticle of T2. NP, notopleural bristle; PS, presutural bristle; SA, supraalar bristle; DC, dorsocentral bristle; SC, scutellar bristle; PA, postalar bristle.

somewhat later stage, muscles form between adjacent sets of these cells, suggesting that the cells are at least involved in the muscle attachment process, if they are not indeed muscle attachment cells. Consistent with ABD-BII being expressed in subsets of ectodermal cells in the embryonic abdomen, $\mathrm{Tab} /+$ flies have on abdominal segments A2-A5 inclusive patches of cuticle that are homeotically transformed toward segments posterior to A5 (6).

\section{DISCUSSION}

Our results indicate that the ABD-BII protein shares with each of the other homeodomain proteins of the BX-Cnamely, UBX, ABD-A, and ABD-BI-the ability to program development of abdominal cuticle, presumably by turning on one or more downstream target genes. Since only ABD-BII is expressed in the wing discs of $T a b /+$ animals, yet T2 has abdominal characteristics normally developed under control of ABD-BI, we conclude that ABD-BII shares with ABD-BI the ability to activate genes required for developing the sexually dimorphic pattern of the posterior abdomen. This sharing of similar functions by homeotic gene products is known for the development of other structures, such as formation of the longitudinal tracheal trunks (1) and suppression of chitinized plates (21).

In some cases, the BX-C proteins appear to have unique, as well as shared, functions-e.g., UBX under control of the bithoraxoid $(b x d)$ cis-regulatory region suppresses ventral pits in the abdominal segments (1). Similarly, ABD-BII appears to have at least one unique function-programming development of genitalia. Thus, animals lacking this protein-namely, homozygotes for the infraabdominal 9 mutant iab-91065_occasionally survive as adults and lack internal and external genitalia (11). Heterozygotes for $T a b$ and such iab-9 mutants also lack genitalia (6), as is expected since the $T a b$ breakpoint in $89 \mathrm{E}$ interrupts the transcription unit encoding ABD-BII (Fig. 2). The iab- $-8^{D 14}$ mutant of Duncan is a 396-bp deletion spanning the promoter of the transcription unit encoding ABD-BI $(11,12)$. Homozygotes for this mutant survive, although rarely, and possess genitalia, showing that ABD-BI protein is not required for their development.

In spite of the ability of ABD-BII to promote development of genitalia in the terminal abdominal regions, no trace of such development is visible in $\mathrm{T} 2$ of $\mathrm{Tab} /+$ adults. However, for such development to occur it may be necessary for ABD-BII to be expressed in conjunction with one or more proteins that are only expressed in the terminal body regions [see reviews by Lipshitz (22) and St. Johnson and NussleinVolhard (23)]. We would predict that protein(s) of the latter types would have to be ectopically expressed along with ectopic expression of ABD-BII before genitalia could develop in T2 of Tab/+ animals. [Two BX-C mutants, tumorous head $(t u-h)(24)$ and SGA-62 (25), are reported to express rudiments of genitalia ectopically but only in the head region and with incomplete penetrance and variable expressivity.]

Unlike most gain-of-function mutants, $T a b$ has complete penetrance and constant expressivity. The archetypal example of a dominant, homeotic, gain-of-function mutant is 

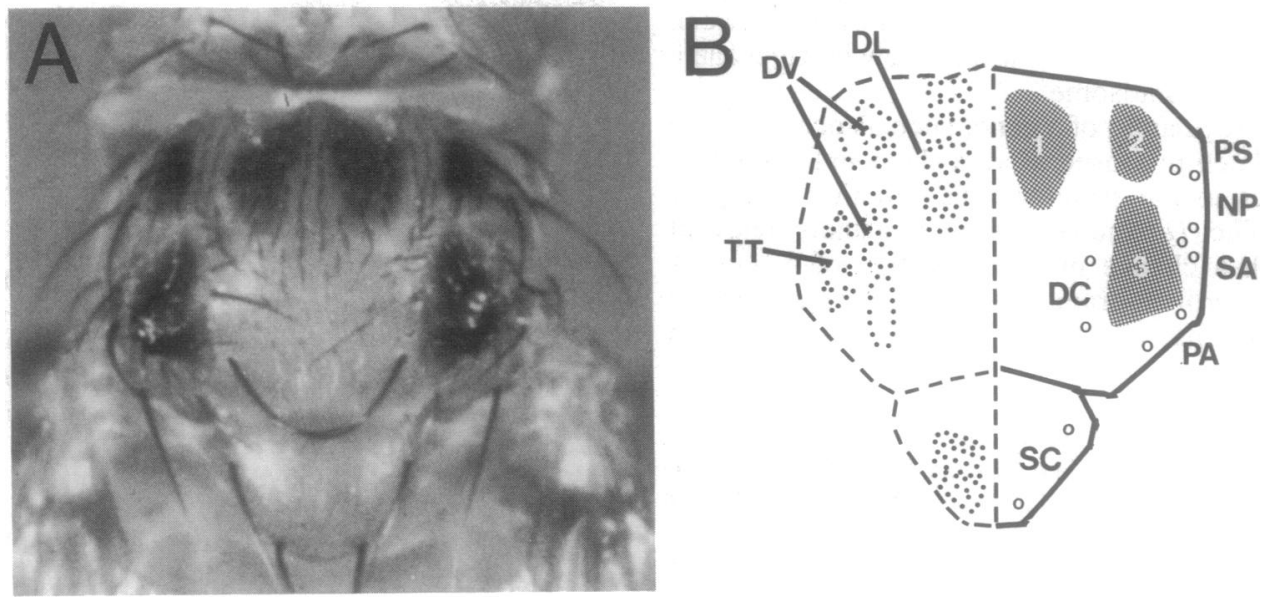

Fig. 4. Comparison of location of islands of abdominal-like cuticle in dorsal $T 2$ of $T a b /+$ with the location of subsets of thoracic muscle attachment sites in dorsal T2 of wild type. $(A) T a b /+$ male thorax. (B) Diagram of T2 as shown in $A$. On the right half, the islands are numbered in agreement with Fig. $3 D$ and small open circles represent sites of macrochetes; on the left half, thoracic muscle insertion sites immediately underlying the cuticle are enclosed in dotted lines [modified from Miller (16)]. DC, dorsocentral bristle; DL, dorsal longitudinal muscle; DV, dorsoventral muscle; NP, notopleural bristle; PA, postalar bristle; PS, presutural bristle; SA, supraalar bristle; SC, scutellar bristle; TT, tergotrochanteral muscle.

Antennapedia (Antp). Although some alleles have complete penetrance, even the most extreme allele, Antp ${ }^{Y u}$, has variable expressivity; that is, only rarely are both antennae of an Antp ${ }^{Y u}$ / + animal transformed toward a full leg. In the BX-C, Haltere mimic $(\mathrm{Hm})$ and Miscadastral pigmentation $(\mathrm{Mcp})$ do have complete penetrance and constant expressivity and represent striking gain-of-function mutations. However, the gain of function extends only to one segment anterior to that in which the function is normally expressed, whereas the $T a b$ transformation is expressed in anterior T2, which is 9 segments anterior to A9 where ABD-BII is normally first expressed.

Evolutionary Considerations. $T a b$ is remarkable among dominant homeotic mutants in a number of ways. It results in an extension of sexually dimorphic traits into the dorsal thorax of the adult, where it could clearly play a role in the sexual behavior of the organism and therefore might under some circumstances have a selective advantage.
$T a b$ represents a dominant gain-of-function mutant that alters the cis regulation of a gene encoding ABD-BII, one of two proteins of the $A b d-B$ domain of the BX-C. In doing so, $T a b$ does not appear to alter the ABD-BII protein itself but, instead, radically alters where that protein is expressed, at the same time eliminating its expression in the terminal abdomen. A macromutation will generally, as in the case of $T a b$, represent loss of an "old" gene function and gain of a "new" one. Since the old function will seldom be a dispensable one, such a mutant will tend to be lethal when homozygous and can be maintained in a population only over a chromosome containing the wild-type allele. If a duplication for the wild-type allele is already present in the species at the time the mutation to a new function arises, then obviously the resultant mutant can immediately become viable as a homozygote. Otherwise, a duplication containing one copy of the mutant allele and one copy of the wild-type allele would need to arise later and could do so by a number of mecha-

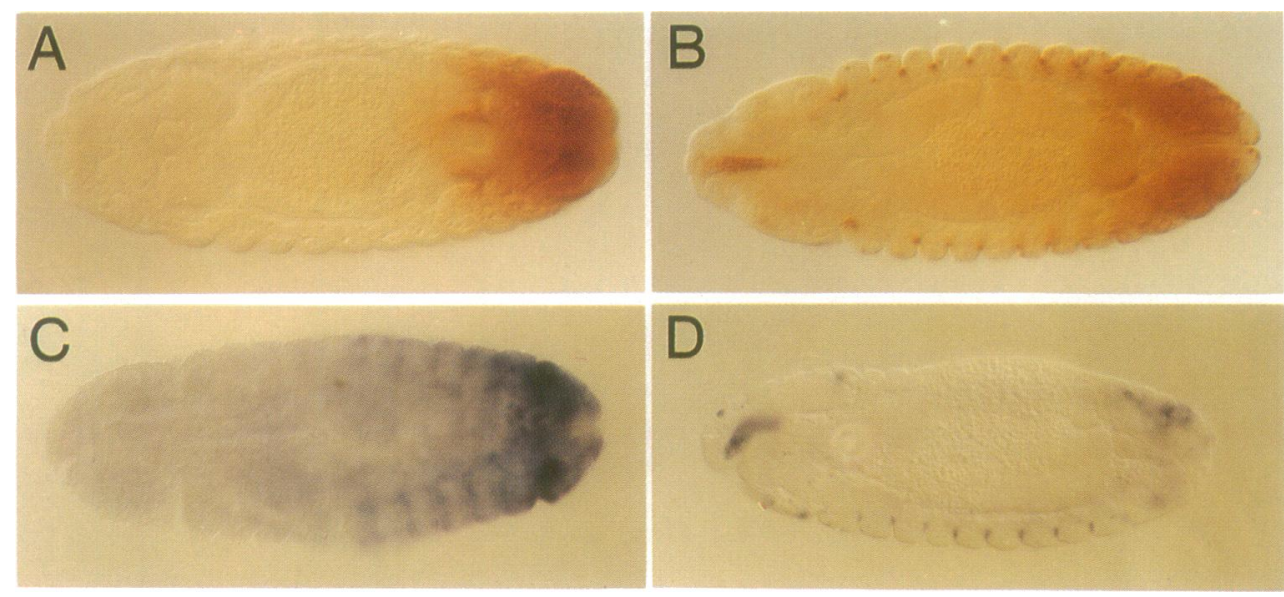

Fig. 5. ABD-B protein and $A b d-B$ transcript expression in wild-type and Tab/+ heterozygous embryos that are $10 \mathrm{hr}$ old. (A) Wild type. ABD-B proteins are expressed in parasegment 10 (PS10)-PS15 inclusive and in visceral mesoderm surrounding the hindgut (4, 15, 17). [Embryonic parasegments are one-half segment offset from the adult segments-e.g., PS10 comprises posterior A4 and anterior A5 (18).] (B) $T a b /+$. Superimposed on the ABD-B protein pattern in A, ectopic expression of that protein is observed in PS8 and PS9, the gnathal region that gives rise to the pharynx and in a laterally localized pattern repeated in each abdominal segment. (C) Tab/+. Transcripts encoding ABD-BI are restricted to the ectoderm of PS8-PS13. Since Tab was induced on a chromosome containing the double mutant Miscadastral pigmentation $(M c p)$ (1) and Super-abdominal (Sap) (19), transcripts encoding ABD-BI show an extension of their wild-type embryonic expression pattern (9, 20) into PS8 and PS9. (D) Tab/+. Transcripts encoding ABD-BII follow the same ABD-B protein expression in the gnathal region of the head and in restricted regions in the remaining segments from PS4 to PS15. Anterior is to the left. $(A-C)$ Dorsal views. $(D)$ Lateral. view. 
nisms, such as an illegitimate recombination event between the mutant gene in one chromosome and the wild-type allele in the homologous chromosome.

Altering the cis regulation of a gene, such as occurs in the $T a b$ mutant, has been proposed as a mechanism for producing major changes in the structure and function of higher organisms (26). The Tab mutant is an unusually relevant example in which a change in cis regulation of a homeodomain-containing protein dramatically alters cell fate and in doing so creates an unusual pattern of sexual dimorphism in the Drosophila thorax.

We thank S. Sharma, J. Hardwick, and H. Park for technical assistance; A. Chopna and K. Vijayraghavan for bringing the embryonic expression pattern of the B14 P-element insertion to our attention; and Welcome Bender, Nancy Bonini, Howard Lipshitz, and Joanne Topol for comments on an earlier draft of this paper. This work was supported by grants to E.B.L. from the National Institutes of Health (HD06331 and GM40499) and from the Lucille P. Markey Charitable Trust.

1. Lewis, E. B. (1978) Nature (London) 276, 565-570.

2. Sanchez-Herrero, E., Vernos, I., Marco, R. \& Morata, G. (1985) Nature (London) 313, 108-113.

3. Duncan, I. (1987) Annu. Rev. Genet. 21, 285-319.

4. Celniker, S. E., Keelan, D. J. \& Lewis, E. B. (1989) Genes Dev. 3, 1425-1437.

5. Scott, M. P., Tamkun, J. W. \& Harzell, G. W. (1989) Biochim. Biophys. Acta 989, 25-48.

6. Celniker, S. E. \& Lewis, E. B. (1987) Genes Dev. 1, 111-123.

7. Tautz, D. \& Pfeifle, C. (1989) Chromosoma 98, 81-85.
8. DeLorenzi, M., Ali, N., Saari, G., Henry, C., Wilcox, M. \& Bienz, M. (1988) EMBO J. 7, 3223-3231.

9. Kuziora, M. A. \& McGinnis, W. (1988) EMBO J. 7, 3233-3244.

10. Karch, F., Weiffenbach, B., Peifer, M., Bender, W., Duncan, I., Celniker, S., Crosby, M. \& Lewis, E. B. (1985) Cell 43, 81-96.

11. Celniker, S. E., Sharma, S., Keelan, D. \& Lewis, E. B. (1990) EMBO J. 9, 4277-4286.

12. Zavortink, M. \& Sakonju, S. (1989) Genes Dev. 3, 1969-1981.

13. Bellen, H., O'Kane, C., Wilson, C., Grossniklaur, U., Pearson, R. K. \& Gehring, W. J. (1989) Genes Dev. 3, 1288-1300.

14. Bryant, P. J. (1975) J. Exp. Zool. 193, 49-78.

15. DeLorenzi, M. \& Bienz, M. (1990) Development 108, 323-329.

16. Miller, A. (1950) in Biology of Drosophila, ed. Demerec, $M$. (Wiley, New York), pp. 368-419.

17. Boulet, A. M., Lloyd, A. \& Sakonju, S. (1991) Development 111, 393-405.

18. Martinez-Arias, A. \& Lawrence, P. A. (1985) Nature (London) 313, 639-642.

19. Sakonju, S., Lewis, E. B. \& Hogness, D. (1984) Genetics 107 , s93.

20. Sanchez-Herrero, E. \& Crosby, M. A. (1988) EMBO J. 7, 2163-2173.

21. Duncan, I. (1982) Genetics 100, s20.

22. Lipshitz, H. (1991) Curr. Opin. Cell Biol. 3, 966-975.

23. St. Johnston, D., Beuchle, D. \& Nusslein-Volhard, C. (1991) Cell 66, 51-63.

24. Kuhn, D., Woods, D. F. \& Andrew, D. J. (1981) Genetics 99, 99-107.

25. Awad, A. A. M., Gausz, J., Gyurkovics, H. \& Parducz, A. (1981) Acta Biol. Acad. Sci. Hung. 32, 219-228.

26. King, M. \& Wilson, A. C. (1975) Science 188, 107-116. 